\title{
Experimental Analysis of the Impact of Particles on the Cavitating Flow
}

\author{
Boštjan Gregorc ${ }^{1, *}$ - Andrej Predin ${ }^{2}$ - Drago Fabijan ${ }^{3}$ - Roman Klasinc ${ }^{4}$ \\ ${ }^{1}$ Dravske elektrarne Maribor, Slovenia \\ 2 University of Maribor, Faculty of Energy Technology, Slovenia \\ ${ }^{3}$ Litostroj Power d.o.o., Slovenia \\ ${ }_{4}^{4}$ Graz University of Technology, Austria
}

The purpose of this paper is to present an analysis of the impact of solid particles on the development of cavitating flow conditions around a hydrofoil. Experimental studies have been conducted in a cavitation tunnel with three different mixtures of particles and water. We used particle-like properties such as are found in river water, and with increasing mass concentration. We performed measurements of torque and the relative noise in the hydrofoil. The point in the formation of vapour phase on the hydrofoil and the pronounced frequency effect were determined by measuring the relative noise. Based on the analysis the results show that the particles increase the intensity and extent of cavitation.

Keywords: particles, cavitation, noise, measurements

\section{O INTRODUCTION}

Operation of water turbines and pumps in the natural environment depends on the seasonal changing of physical and biological properties of water (temperature, viscosity, surface tension, the content of dissolved and non-dissolved air content of impurities). As the flow of rivers and streams changes, so does the amount of impurities (particles) in water. A stronger local rainfall caused to 30 -fold increase of impurities in water depending on underlying conditions. The lifetime of hydraulic machinery is highly dependent on the quality of the media (water). The effect of dirt (mud) in the water in most cases occurs in the form of wear and tear of mechanical parts, and leaks in the connection between rotating and fixed parts. It also causes and increases the risk of cavitation due to impurities and gases under specific conditions (pressure, velocity) [1] and [2]. The impact of cavitation in hydraulic machinery represents a loss of energy with regard to the optimal operating conditions. In the case of the operation of water turbines, the effect of cavitation results in reduced utilization, increased noise and vibration, as well as mechanical damage to the turbine runner surfaces and other exposed areas [3].

Determination of the efficiency changes on prototypes caused by impurities in the water is difficult to achieve from the perspective of performance measurement. Constantly changing various parameters (oscillations of generating power pulsations, pressure, difference in altitude, temperature, air content and mass concentrations of particles) affect the credibility of the results [4] and [5]. The change in turbine efficiency is detected only over time, during which cavitation abrasion damage to surfaces are already present. For these variations of parameters in the case of the prototypes, we studied the influence of the particles in water on the development of cavitation on hydrofoil in the laboratory. Due to controlled parameters at the inlet of the tunnel, we used particles of known diameter, density and mass concentration. With this we came closer to reality state in river water.

\section{MULTI-PHASE FLOW INFLUENCE ON HYDRAULIC MACHINERY OPERATING PROPERTIES}

Research related to the movement of liquids and particles in the transition through the pump and turbine has been conducted by many authors [6] and [7]. For research, different material particle concentrations have been used, as well as various basic materials surfaces [8]. For the evaluation of developments and implications in the process of developing cavitation and abrasion, authors use CCD cameras - visualization, PIV Technology, methods of weighing and vibrations methods [2] to [9].

Authors of other studies have discovered a number of instabilities, among which the pulse cavitation cloud [1] and [10] is the most frequently addressed. In recent decades, research has been based on the mutual interaction between the liquid and the vapour phases. Mei et al. [6] and Shengcai [9] discovered that cavitation in water occurs earlier due to the presence of particles, in comparison to pure water. The mass concentration $\xi_{c}$ of particles, where the largest increase of the vapour phase occurs, is between 8 and $13 \mathrm{~kg} / \mathrm{m}^{3}$. 
Hydrodynamic cavitation causes a change of resistance, a change of hydromechanical flow properties, thermal and lighting effects, and erosion at streaming areas. During the operation of hydraulic machinery, the most undesirable cavitation is in the form of a cloud. This causes turbine or pump efficiency decrease and mechanical damage as a consequence of high local pressures when the vapour bubbles condense, i.e. implode. During the turbine and/or pump operation, cavitation is detected as a sharp sound that is not constant. A released pressure wave spreads through the vapour phase when the vapour phase collapses and liquid is drawn from a wide range of frequencies. The sound accompanies the basis of increased vibration in the occurrence of cavitation. Vibration and noise are the consequences of the shock-wave that is spreading in space and striking in the surrounding area. The noise is generated when bubbles collapse and is located in the high frequency band. Capturing cavitation noise is highly dependent on the position of installing the sensor.

Detection of cavitation noise forms the basis to determine the impact of particles on the development of cavitating flow (initial cavitation).

\section{HYDRAULIC FORCES ON THE HYDROFOIL}

With the creation of multi-phase flow in mixed streaming flow, changing forces are observed around hydrofoil. The flow of water and particles causes a change of the lift force Eq. (1) and drag force Eq. (2), and consequently, torque Eq. (3). The forces could be written as:

$$
\begin{aligned}
& F_{l}=C_{L} \cdot\left(B \cdot L \cdot \rho \cdot v_{\infty}^{2} / 2\right), \\
& F_{d}=C_{D} \cdot\left(B \cdot L \cdot \rho \cdot v_{\infty}^{2} / 2\right), \\
& M_{t}=C_{M} \cdot\left(B \cdot L^{2} \cdot \rho \cdot v_{\infty}^{2} / 2\right),
\end{aligned}
$$

where $C$ is coefficient, length of the profile is $\mathrm{L}$, the width is $B$, and $v_{\infty}$ is the free stream velocity.

Characteristic surface $(A=B \cdot L)$ is equal to the projection of the hydrofoil in a plane which is perpendicular to the free stream velocity. Lift and drag are a result of the distribution of pressure and shear forces. When the condition is $p_{m} \leq p_{v}$, and at an appropriate velocity at the suction side of the hydrofoil, a vapour phase is developed. Initial cavitation number is expressed as Eq. (4):

$$
\sigma=\left(p_{\infty}-p_{v}\right) /\left(\rho \cdot v_{\infty}^{2} / 2\right) \text {. }
$$

The impact of the vapour phase is reflected in the lift and drag force, which depends on the development of the vapour phase.

Determination of changes in pressure based on the relative motion of particles can only be approximated. The movement of particles in the body part streaming and changing its direction. Basically, the following can be written:

$$
Q_{m} \rho_{m}=Q_{d} \rho_{d}+Q_{l} \rho_{l},
$$

where $Q_{m}$ is suspension flow rate, $Q_{l}$ is water flow rate and $Q_{d}$ is flow rate of dispersed particles.

Suppose that a mixture of water with particles, and water without particles have the same pressure and velocity $\left(p_{0 m}=p_{0 l}, v_{0 m}=v_{0 l}\right)$ at the entrance through the plane $0-0$, which is perpendicular to the direction of speed. In the area of minimum pressure on the hydrofoil at the plane 1-1, the conditions are different $\left(p_{1 m} \neq p_{1 l}\right)$. Using an energy approach for moving plane from 0 to a plane 1 the following can be written:

$$
\begin{gathered}
\frac{p_{0 m}-p_{1 m}}{\rho_{m} g}+\frac{v_{0 m}^{2}-v_{1 m}^{2}}{2 g}= \\
=\frac{\left(v_{0 p}^{2}-v_{1 p}^{2}\right)+\left(v_{0 l}^{2}-v_{1 l}^{2}\right)}{2 g}+\frac{p_{0 l}-p_{1 l}}{\rho_{l} g} .
\end{gathered}
$$

Assume that velocities $v_{1 p} \approx v_{1 m} \approx v_{1 l}$ are in the same mixture because of the distance between the particles, $\left(L / d_{d}\right)>1$ and low concentrations of dispersed particles. The assumption is the case of natural river water, where the maximum mass concentration in most cases does not exceed $\xi_{c}=1$ $\mathrm{kg} / \mathrm{m}^{3}$. For this reason, we ignore the interactions between particles. Considering this fact, the velocity differences in the Eq. (6) disappear. Eq. (6) can be written using $p_{0}-p_{1}=\Delta p$, as:

$$
\frac{\Delta p_{m}}{\rho_{m} g}=\frac{\Delta p_{l}}{\rho_{l} g} \Rightarrow \Delta p_{m}=\frac{\rho_{m}}{\rho_{l}} \Delta p_{l} .
$$

The ratio of densities of mixture and pure water influence the pressure change of the mixture. By increasing the concentration, the influence on the development of vapour phase condition $\left(p_{m}-p_{v}(T)=\Delta p\right)$ is achieved.

\section{EXPERIMENT}

We have performed tests on a small cavitation tunnel. The tunnel was designed to study the development of cavitation in various forms of hydraulic hydrofoils. 


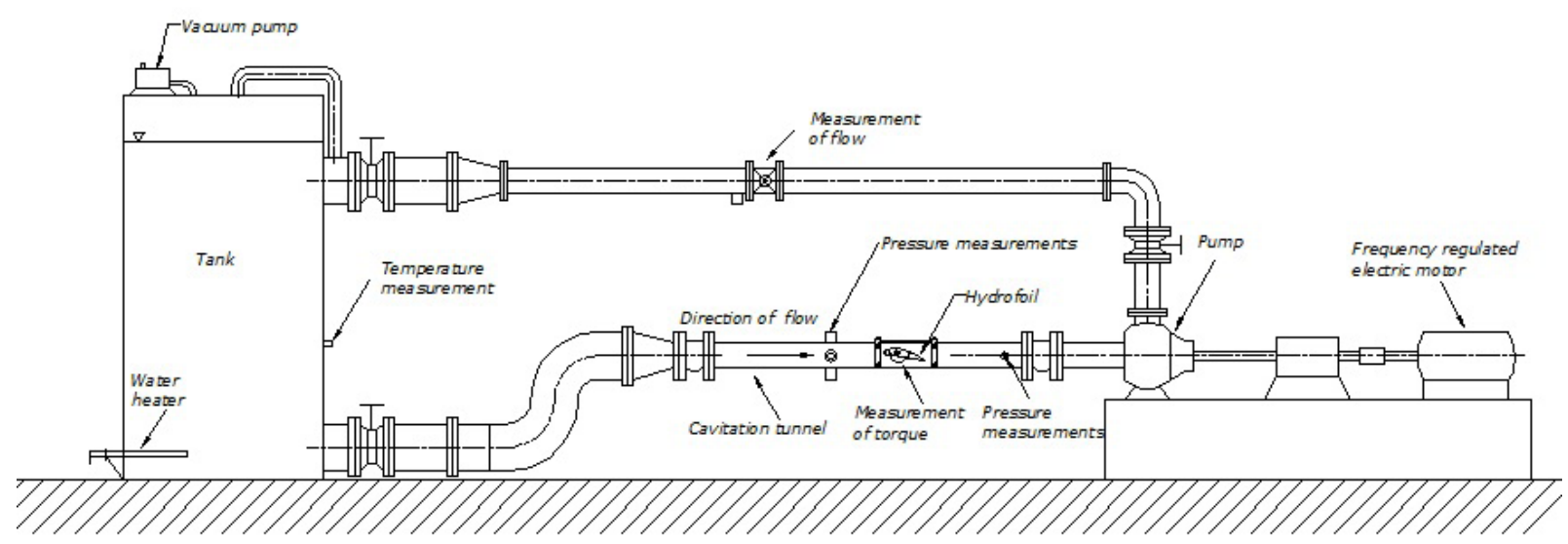

Fig. 1. Cavitation tunnel sketch

It is a closed type and allows mass flow up to $Q_{i}=$ $22 \mathrm{~kg} / \mathrm{s}$ in the tunnel (Fig. 1). The cavitation number change is performed by the controlled application of pressure $p$ in the system. Flow rate is measured using an ultrasonic flowmeter.

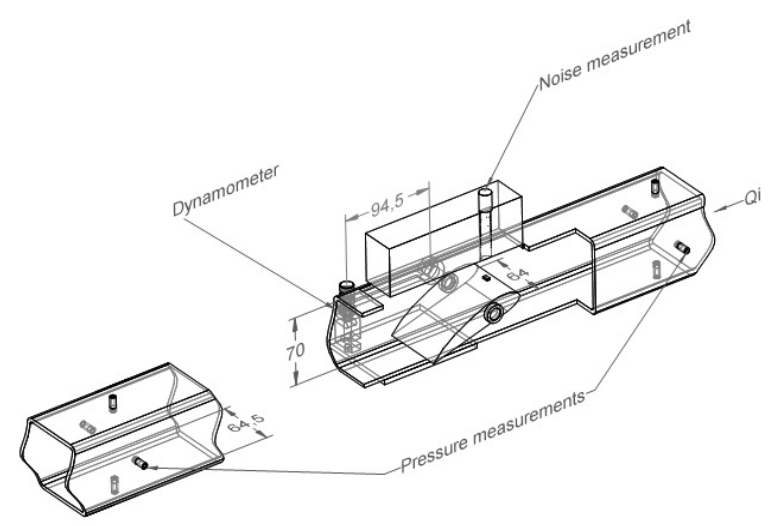

Fig. 2. Geometry of cavitation tunnel and testing hydrofoil

The length of the blade profile is $L_{0}=104 \mathrm{~mm}$ and the width is $\mathrm{B}=64 \mathrm{~mm}$ (Fig. 2), overall length ( $l$ $\left.=17 \times L_{0}\right)$ of the cavitation plane is part of the tunnel $(64.5 \times 70 \mathrm{~mm})$. The hydrofoil was observed through the Plexiglas on the two perpendicular sides. The change in lift and drag forces were measured via changes in a torsion lever attached to the shaft on a fixed hydrofoil and a dynamometer accuracy of $0.1 \%$ (Ahlborn K-25). The link shaft and the dynamometer placed with cantilever handle with a length of 94.5 $\mathrm{mm}$. The pressure in the channel was measured before and after the hydrofoil. The measurements were performed at different flow velocities (average) in the tunnel $(2.6,2.9,3.3$ and $3.6 \mathrm{~m} / \mathrm{s})$. Measurements were conducted at two different angle settings of the hydrofoil $\left(16\right.$ and $\left.20^{\circ}\right)$. The water temperature in the system was $20 \pm 1{ }^{\circ} \mathrm{C}$. By reducing pressure in the system, the decrease in the cavitation number is influenced, thus increasing the developed vapour phase. Measurement of lift and drag forces $\left(M_{t}\right)$ was conducted without addressing the relative friction in the bearings (roller bearings). Visual monitoring of initial cavitation was performed on a metal hydrofoil block (Fig. 2) located in the middle part of the input hydrofoil surface (nozzle is square: $4 \times 2 \times 6 \mathrm{~mm}$ ). The block was located $12 \mathrm{~mm}$ from the inlet edge of the hydrofoil.

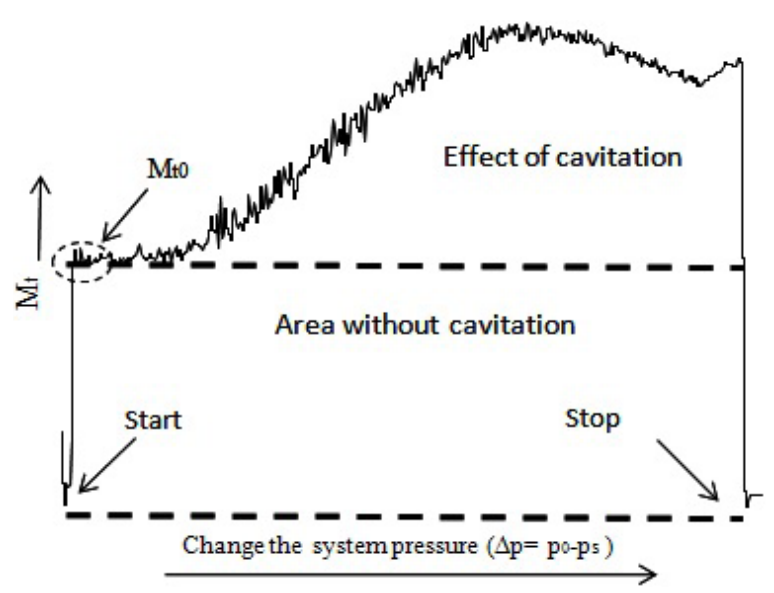

Fig. 3. A case measurement $M_{t}$ of the profiled testing hydrofoil

Torque is shown as $M_{t} / M_{t 0}$, where the ratio represents the initial state without cavitation $M_{t 0}-$ $\Delta p=0$ bar (average in time $\Delta t=10 \mathrm{~s}$ ) and Mt which depends on the reduction of pressure $p_{s}$. The boundary between the influence of cavitation and non-developed area of cavitation can be clearly observed (see Fig. 3). 
Cavitation noise has been measured with the instrument (Cirrus Research plc - CR: 800B) mounted above the Plexiglass and isolated from its surroundings with Styrofoam. The sensor was placed away from the occurrence of vapour phase on the hydrofoil from 11 to $13 \mathrm{~mm}$. Cavitation noise was measured in various frequency ranges (from 25 to $16 \mathrm{kHz}$ ), and at various cavitation numbers. Measurements were started with pure water (tap water), and continued with three different mass fractions of particles. The pressure in the channel was measured before and after the hydrofoil.

Estimated measurement errors for pure water $\left(M_{t} / M_{t 0}\right)$ and for three mass fractions are evident in Table 1.

Table 1. Particle mass fraction used in the experiment and measurement errors - $M_{t} / M_{t 0}$

\begin{tabular}{clc}
\hline Mass fraction & $\xi[-]$ & $\begin{array}{c}\text { Estimated measurement } \\
\text { errors STDEV }(\Delta \mathbf{p}=\mathbf{0} \text { bar })\end{array}$ \\
\hline Pure water & $\xi=0$ & 2.1 \\
\hline Fraction 1 & $\xi=0.001$ & 2.9 \\
\hline Fraction 2 & $\xi=0.0016$ & 3.1 \\
\hline Fraction 3 & $\xi=0.0032$ & 3.6 \\
\hline
\end{tabular}

For measuring the impact on the development of cavitation, we used particles of material FR 240/F. The density of particles is $\rho_{d}=1700 \mathrm{~kg} / \mathrm{m}^{3}$, (diameter of the used particles is between $25<d_{d}<35 \mu \mathrm{m}-$ the mean diameter of particles is $30 \mu \mathrm{m}$ ); they are insoluble in water, inert and do not oxidise. Particle density $\rho_{d}$ and the mean diameter of particles dd were chosen because of similar qualities of particles in the rivers in our geographic area. All measurements were performed at the same conditions (mass flow, the reference pressure in the system, temperature).

\subsection{Results and Discussion}

Experimental measurements are shown as a relative comparison between the particle-free water and state water with particles.

The results of the occurrence of cavitation - $\sigma$ on hydrofoil (pure water) at experimental measurements are comparable to results of other authors [7] and [10].

Fig. 4 shows an increase in torque (ratio) $M_{t} /$ $M_{t 0}$ by the addition mass fractions of particles in suspension. The difference between $M_{t} / M_{t 0}$ of clean water and a suspension of particles is greater in the case of small inclination angles of the hydrofoil (Fig. 5).

Torque increases above the difference pressure of $\Delta p=0.15$ bar (Fig. 5).
The part of Fig. 6 shows that the largest change in momentum can also be seen in the maximum mass fraction $(\xi)$ of particles in the water. The experimental data is shown as a relative change of $M_{t} / M_{t 0}$ in the reduction of the dependence on pressure $\Delta p$ (lower cavitation number). The change in $M_{t} / M_{t 0}$ for $\Delta p=$ 0.15 is lower in case of pure water, compared to the mixture of particles and water. The increase of $M_{t} /$ $M_{t 0}$, caused by additional particles, is the largest in the range of $\Delta p=0.2$ to 0.3 bar, where the difference is $11 \% . M_{t} / M_{t 0}$ begins to reduce with the increase of $\Delta p(\Delta p=0.32$ bar $)$, due to the intensity of the vapour in the suction side of hydrofoil. The relative mass fraction between 0.001 and 0.0016 shows the same trend of increasing a relative change of $M_{t} / M_{t 0}$.

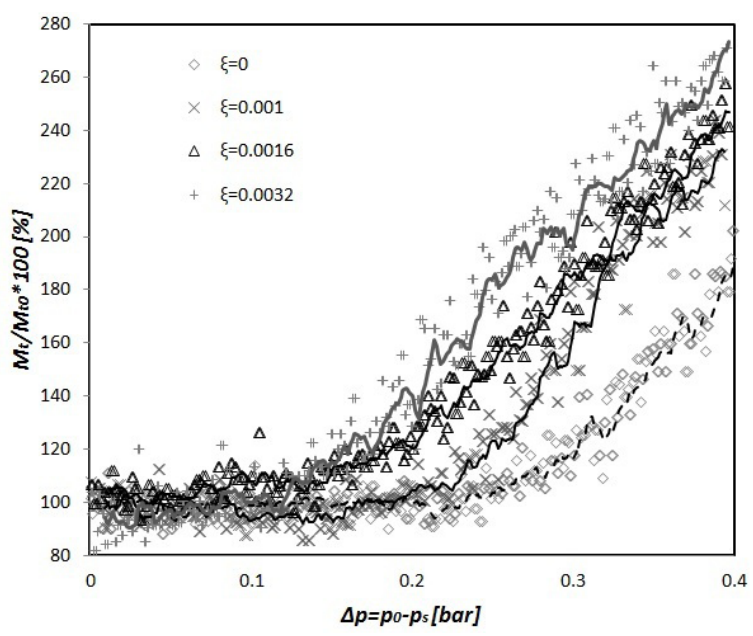

Fig. 4. The impact of mass fraction of particles to change $M_{t} / M_{t 0}\left(v_{s u}=3.6 \mathrm{~m} / \mathrm{s}, \alpha=16^{\circ}\right)$

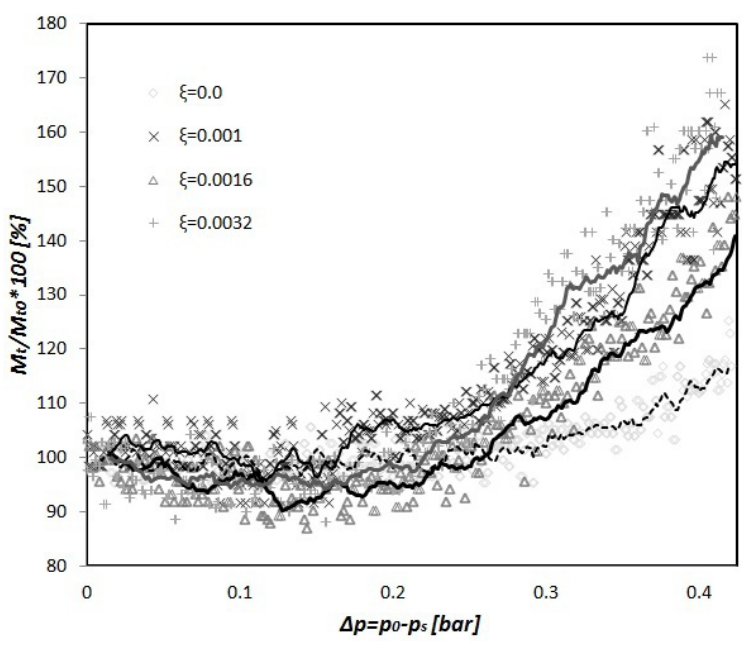

Fig. 5. The impact of mass fraction of particles to change $M_{t} / M_{t 0}$

$$
\left(v_{s u}=2.6 \mathrm{~m} / \mathrm{s}, \alpha=20^{\circ}\right)
$$


Fig. 7 shows the variation of the formation of vapour phase of the mass fraction of particles (measurement of the relative noise). We see that a vapour phase occurs at relatively the same flow conditions $\left(\Delta p, v_{s u}\right)$. Particles in suspension increased the intensity of occurrence of cavitation.

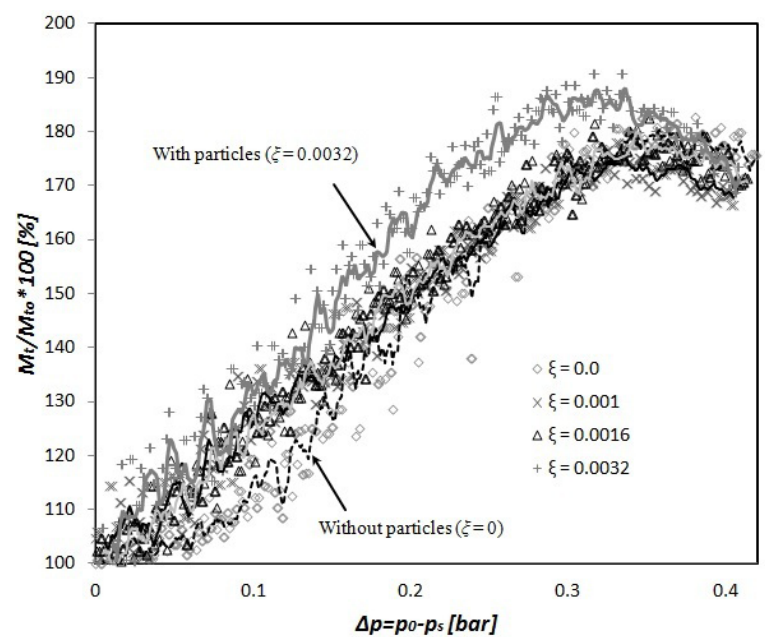

Fig. 6. Experimental comparison of torque and $\Delta p$ on hydrofoil, using pure water and suspension with particle $\left(v_{s u}=3.3 \mathrm{~m} / \mathrm{s}\right.$, $\alpha=20^{\circ}$ )

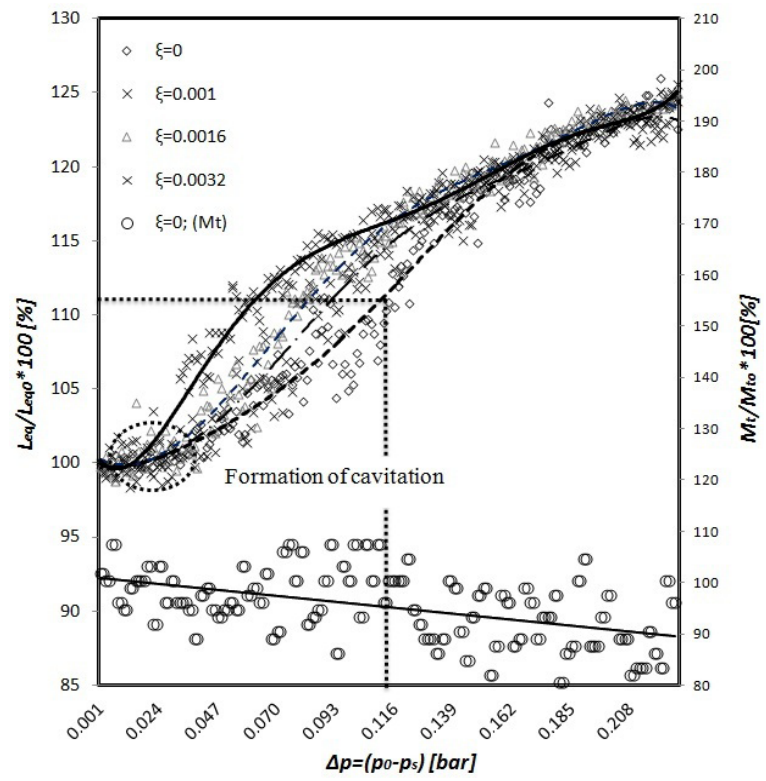

Fig. 7. Dependence of cavitation formation of the mass concentration of particles in suspension $\left(\sigma_{s u}=2.6 \mathrm{~m} / \mathrm{s}, \alpha=16^{\circ}\right)$

By increasing the relative noise (cavitation) by $15 \%$, changes in torque on the hydrofoil are not detected. In the case of pure water the difference in the change in noise is $7 \%(\Delta p=0.06, \xi=0.0032)$.
Cavitation number is changed by $3.6 \%$ in relatively the same relative intensity noise (Fig. 8). The increase in the vapour phase is estimated by comparing the results of measurements of water free of particles.

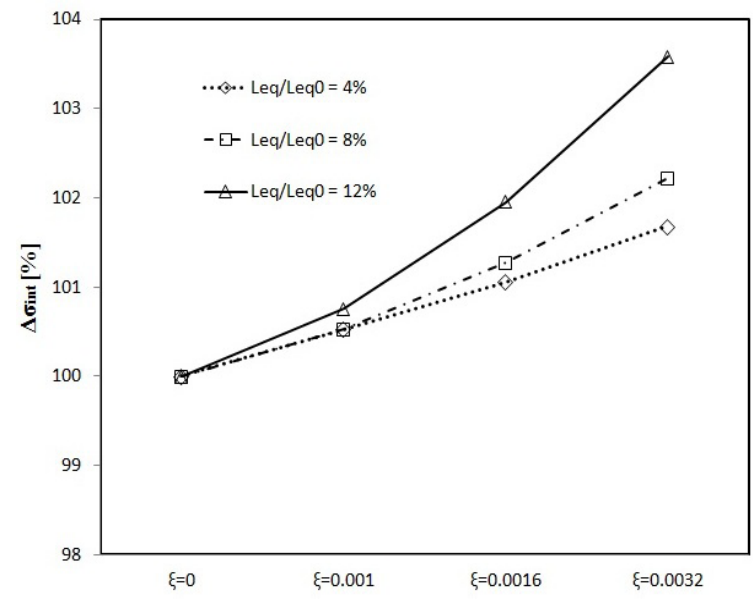

Fig. 8. Changes in the initial cavitation number - $\sigma$ (intensity) on the development of vapour phase $\left(v_{s u}=2.6 \mathrm{~m} / \mathrm{s}, \alpha=16^{\circ}\right)$

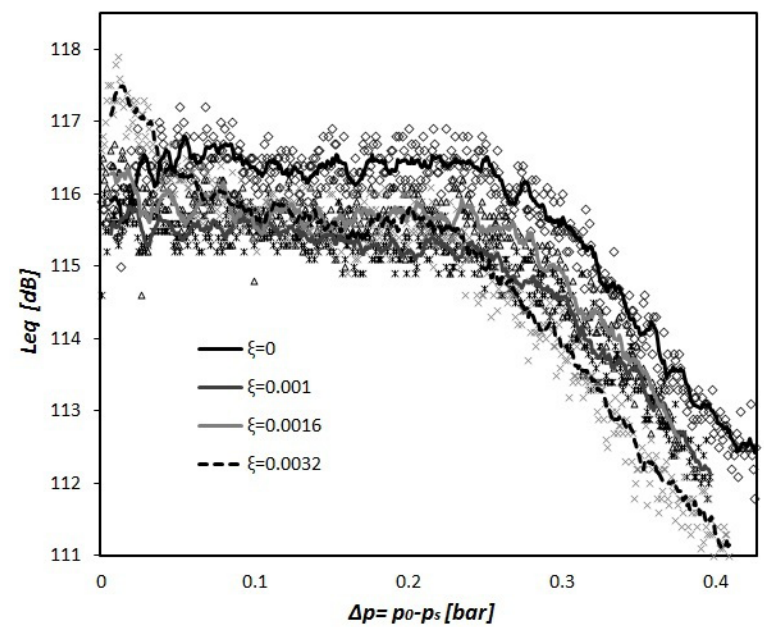

Fig. 9. The impact of mass fraction of particles on the change of relative intensity noise $\left(v_{s u}=3.3 \mathrm{~m} / \mathrm{s}, \alpha=20^{\circ}\right)$

By increasing the vapour cloud (reduced cavitation number) and the mass fraction of particles decreases the relative noise (Fig. 9). We believe that the reduction of the relative noise, impact of increased volume of vapour phase, which reduces the speed of sound. By analyzing the standard deviations the maximum deviation of the relative noise in the area of initial cavitation is found (Fig. 10). By increasing the vapour phase, the standard deviation decreases. 
In all cases (mass concentrations) in the area of maximal developed vapour phase in a suspension the standard deviation is minimal.

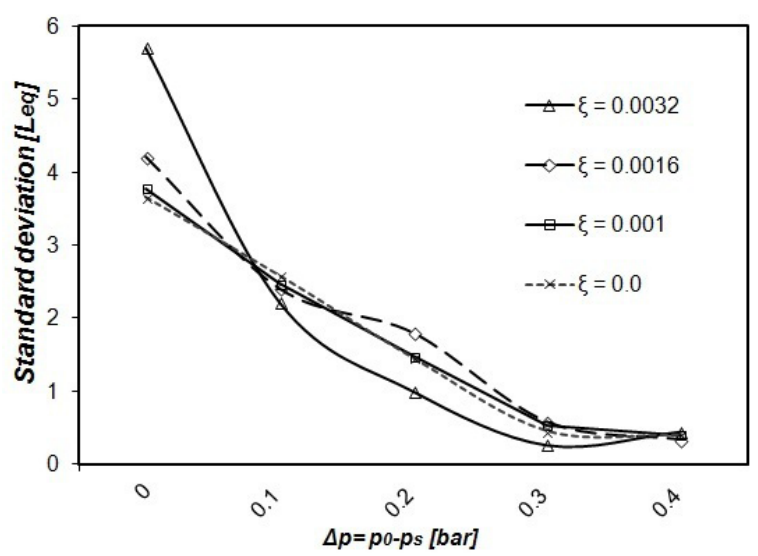

Fig. 10. Standard deviation of noise as a function of changes in mass concentrations and the reference pressure $\left(v_{s u}=2.9 \mathrm{~m} / \mathrm{s}\right.$, $\alpha=16^{\circ}$ )

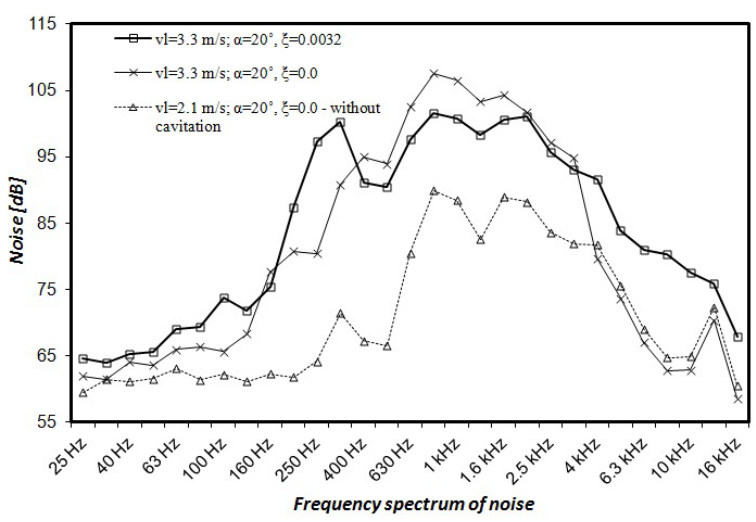

Fig. 11. The impact of particles on the frequency range of cavitation noise

Fig. 11 shows a comparison between the situation where no cavitation and the situation with developed cavitation (without particles and with the particles).

Particles markedly increase the intensity of sound at a frequency of $315 \mathrm{~Hz}$, and the area between 4 and $12 \mathrm{kHz}$. We believe that the particles cause intense tearing vapour clouds at a frequency of $315 \mathrm{~Hz}$. Similar experimental results of relative intensity noise are also recognized by other authors [1] and [10].

\section{CONCLUSIONS}

In the cavitation tunnel, we explored the effect of particles in the water on the change of the relative ratio of torque $\left(M_{t} / M_{t 0}\right)$ and the relative intensity of cavitation - noise on a hydrofoil for three different mass fractions of particles in water. In examining the impact of particles on lift-drag forces and noise, we compared the measured relative values of clean water free of particles. From the measured values, we have drawn the following conclusions:

- Change in torque $\left(M_{t} / M_{t 0}\right)$ depends on the development of vapour phase and the attachment hydrofoil. Development of vapour phase before the centre mounting reduces torque.

- Particles increase the torque on the hydrofoil. By increasing the mass fraction $\xi$ of particles in suspension increases the torque. Increased change in torque between the state of the particles in suspension and pure water is measured at a higher pressure difference (lower cavitation number).

- With the increasing angle of hydrofoil $\left(20^{\circ}\right)$ and suspension velocity in the tunnel, the differences are due to added particles on the lower torque $M_{t} / M_{t 0}$.

- Vapour phase occurs at relatively the same cavitation number in case of pure water and the added particles. Particles in suspension increased the intensity of occurrence of cavitation. By increasing the relative noise (cavitation) by $15 \%$, changes in torque on the hydrofoil are not detected.

- Standard deviation of the relative noise is the largest in the area of initial cavitation. By increasing the vapour phase, the standard deviation decreases.

- The formation of cavitation on the hydrofoil is rapidly detected by increased noise in the range of the occurrence of vapour phase. Noise increases in developed cavitation by $35 \%$, in comparison to the state without cavitation. By measuring the relative noise rapidly the emergence of a vapour phase is detected, as in the case of torque measurement $\left(M_{t} / M_{t 0}\right)$.

- The values of maximum amplitude of noise in frequency areas are reached in the range $-1 \mathrm{kHz}$. Particles markedly increase the intensity of sound at a frequency of $315 \mathrm{~Hz}$, and the area between 4 and $12 \mathrm{kHz}$.

\section{NOMENCLATURE}

$\begin{array}{ll}p_{0} & \text { barometric pressure } \\ p_{s} & \text { system pressure } \\ v & \text { characteristic velocity } \\ \rho & \text { density } \\ d_{d} & \text { mean diameter } \\ T & \text { temperature } \\ \xi_{c} & \text { mass concentration } \\ \xi & \text { mass fraction }\end{array}$


$\alpha \quad$ angle of hydrofoil

$\sigma \quad$ cavitation number

$\sigma_{\text {int }} \quad$ initial cavitation number

$Q_{i} \quad$ flow rate

$C_{D} \quad$ drag coefficient

$M_{t} \quad$ torque

$M_{t} / M_{t 0}$ ratio of torque

STDEV standard deviation

$l_{e q} \quad$ standard deviation of noise

$L_{0} \quad$ length of the profile

\section{Subscripts}

$\begin{array}{ll}l & \text { water phase } \\ d & \text { dispersed phase } \\ m & \text { mixture } \\ s u & \text { suspension }\end{array}$

\section{REFERENCES}

[1] Brennen, C. (1995). Cavitation and bubble dynamics. Oxford University Press, Oxford.

[2] Širok, B., Dular, M., Stoffel, B., Novak, M., Hočevar, M., Ludwig, G., Bachert, B. (2002). The influence of cavitation structures on the erosion of a symmetrical hydrofoil in a cavitation tunnel. Strojniški vestnik Journal of Mechanical Engineering, vol. 7, p. 368-378.

[3] Wang, D., Atlar, M., Sampson, R. (2006). An experimental investigation on cavitation, noise, and slipstream characteristics of ocean stream turbine. University of Newcastle upon Tyne, Newcastle upon Tyne.
[4] Xavier, E., Egusquiza, E., Farthat, M., Avellan, F., Coussirat, M. (2006). Detection of cavitation in hydraulic turbines. Mechanical Systems and Signal Processing, vol. 20, p. 983-1007, DOI:10.1016/j. ymssp.2004.08.006.

[5] Osterman, A., Dular, M., Hočevar, M., Širok, B. (2010). Infrared thermography of cavitation thermal effects in water. Strojniški vestnik - Journal of Mechanical Engineering, vol. 56, no. 9, p. 527-534.

[6] Mei, Z.Y., Wu, Y.L. (1996). Review of research on abrasion and cavitation of silt-laden flow through hydraulic turbine runner in China. Proceedings of the 19th IAHR, Section of Hydraulic Machinery and Cavitation, p. 641-650.

[7] Shengcai, L. (2003). Cavitation enhancement in silt erosion: Obstacles \& way forward, 5th International Symposium of Cavitation, Osaka.

[8] Duan, C.G., Karelin, V.Y. (2002). Abrasive erosion \& corrosion of hydraulic machinery. International Research Center on Hydraulic Machinery, vol. 2, Imperial College Press, London.

[9] Shengcai, L. (2006). Cavitation enhancement of silt erosion - An envisaged micro model. Wear, vol. 260, no. 9-10, vol. 31, p. 1145-1150.

[10] Širok, B., Dular, M., Stoffel, B. (2006). Cavitation, i2, Ljubljana. (in Slovenian)

[11] Keller, A.P., Rott, H.K. (1999). Scale effects on tip vortex cavitation inception. Proceedings of $3 \mathrm{rd}$ ASME/JSME Joint Fluids Engineering Conference, International Symposium On Cavitation Inception, San Francisco. 